\title{
Kırıkkale Üniversitesi’ne Kurulacak Olan Rüzgar Türbini İçin Enerji ve Maliyet Analizinin Yapılması
}

\author{
Özge Pınar ARSLAN, Yağmur ARIKAN, Mustafa Y. ERTEN, Ertuğrul ÇAM
}

Elektrik-Elektronik Mühendisliği Bölümü, Kırıkkale Üniversitesi, Kırıkkale, 71451 Türkiye.

pozge.arslan@gmail.com

\begin{abstract}
Özet - Bu çalışmada, Müsiad'ın Ahiler Ajansı ile ortak yürüttüğü proje kapsamında, Kırıkkale Üniversitesi kampüs alanında bulunan ve rüzgar hızı belirlenen bir bölgenin verileri kullanılarak, bölgenin rüzgar enerjisi potansiyeli analiz edilmiştir. Çalışmada ilk olarak rüzgar enerjisiyle alakalı kavramlar açıklanmış, daha sonra belirlenen rüzgar verisi yardımıyla bölgede kurulabilecek $800 \mathrm{kW'lık} \mathrm{anma}$ gücüne sahip Enercon-53 rüzgar türbinin farklı kule yükseklikleri için enerji analizi ve maliyet analizi yapılmıştır. $\mathrm{Bu}$ analiz yardımıyla kule yüksekliğinin enerji üretim miktarına, kapasite faktörüne ve yatırımın amorti edilebileceği süreye etkisi incelenmiştir.
\end{abstract}

Anahtar Kelimeler: Rüzgar Enerjisi, Rayleigh, Enerji Analizi, Maliyet Analizi, Kırıkkale.

\begin{abstract}
In this study, wind energy potential of the campus of Kırıkkale University is analyzed by using wind speed data which is obtained from the project within the scope of Müsiad and Ahiler Development Agency. Firstly, the concepts related to wind energy are explained, then energy and cost analyses are made through wind speed data for different hub heights of Enercon-53 wind turbine which has $800 \mathrm{~kW}$ rated power. The effect of hub height to the energy production amount, capacity factor, and repayment period of investment is examined by the means of analyses.
\end{abstract}

Keywords: Wind Energy, Rayleigh, Energy Analysis, Cost Analysis, Kırıkkale.

\section{GíRiş}

Ç ağımızın en önemli ihtiyaçlarından biri olan enerji, ülkelerin gelişmişlik düzeyini gösteren en önemli parametrelerin başında gelmektedir. Talep edilen enerjinin hızla artmasina paralel olarak mevcut enerji kaynakları doğada kısıtlı olarak bulunmaktadır. Bununla birlikte artan nüfus ve enerji talebine bağlı olarak dünyanın emisyon değerinin mevcut sinırlar içinde tutulması zorlaşmaktadır. $\mathrm{Bu}$ nedenle, üretilen enerjinin yüksek verimle kullanılması, mevcut enerji kaynaklarının yanı sıra alternatif ve yenilenebilir enerji kaynaklarına ait potansiyelin değerlendirilmesi büyük önem taşımaktadır.
Yenilenebilir enerji kaynaklarından biri de rüzgar enerjisidir. Rüzgar enerjisinin, ham maddesinin bedava olması, enerjide dışa bağımlılığı azaltması, tükenmez ve güvenilir bir kaynak olması ve ekolojik çevreye zarar vermemesi gibi bir çok sebepten dolayı kullanımı giderek artmaktadır ve dünyada yaklaşı 70 ülkenin elektrik üretiminden faydalandığ 1 ve son zamanlarda ülkemizde de hızlı bir gelişim gösteren ve fosil kökenli yakıtlarla elde edilen enerjiye alternatif bir enerji türüdür [1-4]. Öyle ki, dünyada 1996 yılında rüzgar kurulu gücü yaklaşı 6000 MW, 2000'li yıllarda rüzgar kurulu gücü yaklaşık 17000 MW iken günümüzde bu değer yaklaşık $340.000 \mathrm{MW'a}$ ulaşmış durumdadır [2].

Ülkemiz açısından bakıldığında ise, Avrupa'daki bir çok ülkeye kıyasla ciddi bir rüzgar potansiyeline sahip olduğumuz söylenebilir. Ülkemizin sahip olduğu yüksek potansiyel ile birlikte, ülkemizde rüzgar enerjisiyle ilgili yatırımlar son yıllarda artış göstermektedir. Özellikle 2005 yılındaki 'Yenilebilir Enerji Kaynakları Yasası' ve 2011 yılındaki '500 kW'a Kadar Lisansız Elektrik Üretime İlişkin' yasayla beraber rüzgar enerjisine gereken önemin verildiği söylenebilir. Ülkemizin rüzgar kurulu gücü 2005 y1lında yaklaşık $20 \mathrm{MW}$ iken, 2013 yılı itibariyle yaklaşı 3000 MW olup, bu değerin 2023 yılında 20000 MW olmas1 hedeflenmektedir [3-4].

Rüzgar enerjisi sektöründe meydana gelen teknolojik gelişmeler, rüzgar türbini ve bileşenlerinin maliyetlerinin azalması ve ülkemizde rüzgar enerjisine verilen teşviklerin artmasina paralel olarak bu konuda yapılacak olan yatırımların ciddi manada artacağı ve bu konudaki çalışmaların önem kazanacağı düşünülmektedir.

Bu çalışmada, Kırıkkale Üniversitesi Kampüsü araştırma noktası olarak ele alınmış, anma gücü $800 \mathrm{~kW}$ olan Enercon-53 tipi rüzgar türbininin 3 farklı kule yüksekliğine yükseltilmesiyle elde edilebilecek enerji miktarları hesaplanmıştır. Enerji analizi yapıldıktan sonra maliyet analizi yapılarak yatırımların geri ödeme süreleri bulunarak, yatırımın ekonomik yapılabilirliği ölçülmüştür.

\section{RÜZGAR ENERJISI}

Rüzgarın belli bir periyotta değişimi ve dağılımı, enerji üretimi değerlendirmeleri için çok önemlidir. Türbin 
tasarımcıları; türbin iyileştirmesinde ve maliyeti en aza indirmede rüzgar dağılımı ve değişimi ile ilgili bilgilere gerek duyarlar [5].

Rüzgar hızının dağılımının belirlenmesinde en yaygın kullanılan dağılımlar Weibull ve Rayleigh dağılımıdır. Rüzgar hızı için 2 parametreli Weibull dağılımının genel ifadesi,

$$
f_{W}(v)=\frac{k}{c}\left(\frac{v}{c}\right)^{k-1} \exp \left[-\left(\frac{v}{c}\right)^{k}\right]
$$

şeklindedir. Burada $f(v)$ gözlemlenen rüzgar hızı $v$ 'nin olasılık fonksiyonu, $k$ ve $c$ Weibull parametreleridir. Weibull dağılımının birikmiş olasılık fonksiyonu ise,

$$
F_{W}(v)=1-\exp \left[-\left(\frac{v}{c}\right)^{k}\right]
$$

şeklinde ifade edilir. Bu fonksiyon, rüzgar hızının belli bir $v$ değerinden küçük ya da eşit gerçekleşme olasılığını verir.

Weibull olasılık yoğunluk fonksiyonları içerisinden $\mathrm{k}=2$ değerine sahip ve daha gerçekçi bir yapı gösteren olasılık yoğunluk fonksiyonu, Rayleigh olasılık yoğunluk fonksiyonu olarak adlandırılır.

Rayleigh dağılımı ve bu dağılımın birikmiş olasılık fonksiyonu sırasıyla (3) ve (4) eşitlikleri kullanılarak bulunur.

$$
\begin{aligned}
& f_{R}(v)=\left(\frac{\pi}{2}\right)\left(\frac{v}{v_{m}^{2}}\right) \exp \left[-\left(\frac{\pi}{4}\right)\left(\frac{v}{v_{m}^{2}}\right)^{2}\right] \\
& F_{R}(v)=1-\exp \left[-\left(\frac{\pi}{4}\right)\left(\frac{v}{v_{m}^{2}}\right)^{2}\right]
\end{aligned}
$$

Rayleigh dağılım fonksiyonuna göre esme hızı saati ise,

$$
h_{r}=\left(\frac{\pi}{2}\right)\left(\frac{v_{r i}}{v_{\text {rort }}^{2}}\right) \exp \left[-\left(\frac{\pi}{4}\right)\left(\frac{v_{r i}}{v_{\text {rort }}}\right)^{2}\right]
$$

olarak bulunur. Burada $h_{r}$ esme saatini, $v_{\text {rort }}$ bir yerin ortalama hızını, $v_{r i}$ ise herhangi bir rüzgar hızını göstermektedir.

Türbin göbek yüksekliğinde rüzgar ölçümü alınmadığında, ölçüm alınan yüksekliklerdeki rüzgar hızlarının göbek yüksekliğine taşınması Hellman katsayısı yardımıyla sağlanmaktadır. Rüzgar türbinlerinden elde edilmesi beklenen enerji hesabında, birim rüzgar hızı aralığının seçimi ve Hellman katsayısının doğru olarak belirlenmesi çok önemlidir [6]. Uygun bir Hellmann katsayısı kullanılarak, belli bir yükseklikte ölçülen rüzgar hızı değerlerinden, istenen bir yükseklikteki tahmini rüzgar hızı değerleri hesaplanabilir. Belli bir yükseklikte ölçülen rüzgar hızı verileri; aşağıdaki bağıntı kullanılarak başka yüksekliklere aktarılabilir [7]:

$$
V=V_{o}\left(\frac{h}{h_{o}}\right)^{\mu}
$$

Bu bağıntıda kullanılan semboller, aşağıdaki şekilde tanımlanmıştır:

$V$ : hesaplanmak istenen yükseklikteki rüzgar hızı,

$V_{o}$ : ölçüm sonuçları bilinen yükseklikteki rüzgar hızı, $h$ : hesaplanmak istenen noktanın yerden yüksekliği,

$h_{o}$ : ölçüm sonuçları bilinen noktanın yerden yüksekliği, $\mu$ : Hellmann katsayısı.

Rayleigh olasılık yoğunluk fonksiyonu kullanılarak rüzgar hızlarının olasılıkları hesaplanır, bu değerler toplam süreyle çarpılarak rüzgar hızlarının yıl içindeki esme süreleri bulunur. Türbinden elde edilen enerji miktarı ise türbin güç eğrisinde, rüzgar hızına karşılık gelen güç değeri ile esme süresi çarpılarak hesaplanır [8].

Enerji analizi yapıldıktan sonra, bölge için en iyi yatırımı yapabilmek ve bölgeye en uyumlu olabilecek türbin kule yüksekliğini bulabilmek için maliyet analizleri yapılır. Enerji satışı sonucunda türbin toplam maliyetinin karşılandığ́ geri dönüşüm süresi bulunur.

\section{III. ÇALIŞMADA Kullanilan BÖlge VE TÜRBIN ÖZELLIKLLERI}

$\mathrm{Bu}$ çalışma kapsamında, Kırıkkale Üniversitesi Kampüsü araştırma noktası olarak ele alınmıştır. Bölge küçük otların bulunduğu bozkır bir alana sahiptir. 2014 yılında, Müsiad'ın Ahiler Ajansı ile ortak yürüttüğü proje kapsamında, Kırıkkale Üniversitesi kampüs alanında bulunan bölgenin on metre yükseklik için rüzgar hızı 4.5 $\mathrm{m} / \mathrm{sn}$ olarak belirlenmiştir [9]. Türbin olarak $800 \mathrm{~kW} \mathrm{~kW}^{\prime} \mathrm{lk}$ Enercon-53 rüzgar türbini seçilmiștir. Ele alınan Enercon53 türbine ait teknik özellikler Tablo I'de gösterilmiştir [10].

TABLO I

ENERCON-53 RÜZGAR TÜRBININE AiT TEKNIK ÖZELLIKLER

\begin{tabular}{|c|c|}
\hline Anma Gücü & $800 \mathrm{~kW}$ \\
\hline Kule Yüksekliği & $60 \mathrm{~m} / 73 \mathrm{~m} / 75 \mathrm{~m}$ \\
\hline Kanat Çapı & $52.9 \mathrm{metre}$ \\
\hline Kanat Sayısı & 3 adet \\
\hline Kanadın Süpürdüğ̈̈ Alan & $2.198 \mathrm{~m}^{2}$ \\
\hline
\end{tabular}

Şekil I'de, kullandığımız E-53 tipi rüzgar türbini hesaplanmış güç eğrisi, Tablo II'de ise türbinin rüzgar hızına karşılık ürettiği güç ve güç katsayısı gösterilmektedir [10]. 
ŞEKİL I

E-53 TiPI RÜZGAR TÜRBINII GÜÇ EĞRISI VE TÜRBINININ RÜZGAR HIZINA KARSSILIK ÜRETTIĞİ GÜC VE GÜC KATSAYISI

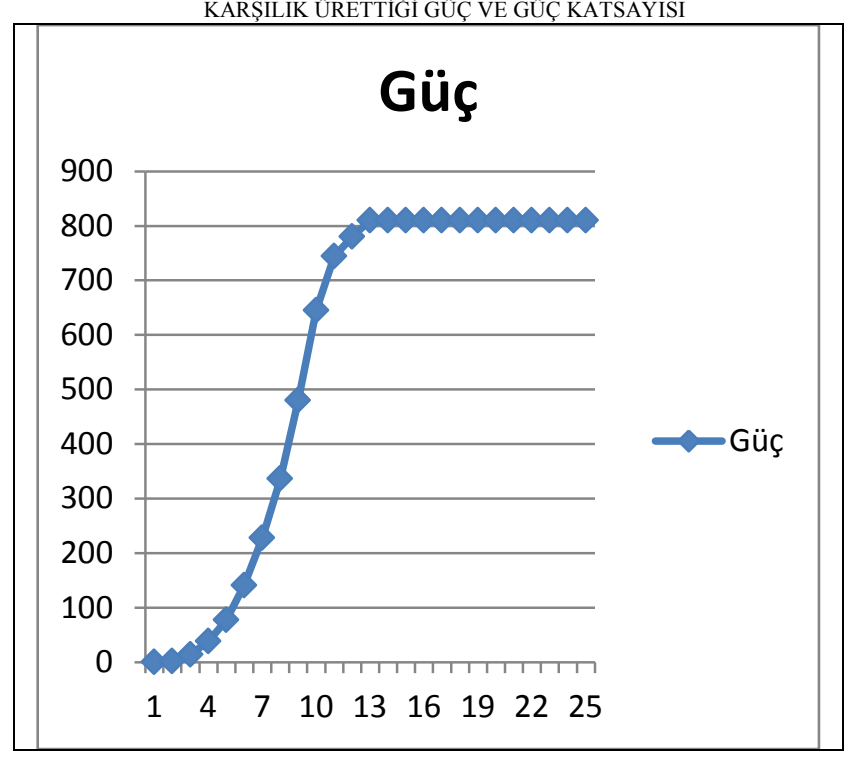

TABLO II

TÜRBININ RÜZGAR HIZINA KARŞILIK ÜRETTIĞI GÜÇ VE GÜÇ KATSAYISI

\begin{tabular}{|c|c|c|c|c|c|}
\hline $\begin{array}{l}\text { Rüzgar } \\
\text { h1z1 } \\
{[\mathrm{m} / \mathrm{sn}]}\end{array}$ & $\begin{array}{l}\text { Güç } \\
{[\mathrm{kW}]}\end{array}$ & $\begin{array}{l}\text { Güç } \\
\text { Katsay1sı } \\
{[-]}\end{array}$ & $\begin{array}{l}\text { Rüzgar } \\
\text { hız1 } \\
{[\mathrm{m} / \mathrm{sn}]}\end{array}$ & $\begin{array}{l}\text { Güç } \\
{[\mathrm{kW}]}\end{array}$ & $\begin{array}{l}\text { Güç } \\
\text { Katsay1s1 } \\
{[-]}\end{array}$ \\
\hline 1 & 0.0 & 0.00 & 14 & 810.0 & 0.22 \\
\hline 2 & 2.0 & 0.19 & 15 & 810.0 & 0.18 \\
\hline 3 & 14.0 & 0.39 & 16 & 810.0 & 0.15 \\
\hline 4 & 38.0 & 0.44 & 17 & 810.0 & 0.12 \\
\hline 5 & 77.0 & 0.46 & 18 & 810.0 & 0.10 \\
\hline 6 & 141.0 & 0.48 & 19 & 810.0 & 0.09 \\
\hline 7 & 228.0 & 0.49 & 20 & 810.0 & 0.08 \\
\hline 8 & 336.0 & 0.49 & 21 & 810.0 & 0.06 \\
\hline 9 & 480.0 & 0.49 & 22 & 810.0 & 0.06 \\
\hline 10 & 645.0 & 0.48 & 23 & 810.0 & 0.05 \\
\hline 11 & 744.0 & 0.42 & 24 & 810.0 & 0.04 \\
\hline 12 & 780.0 & 0.34 & 25 & 810.0 & 0.04 \\
\hline 13 & 810.0 & 0.27 & & & \\
\hline
\end{tabular}

\section{UYGULAMA VE SONUÇLAR}

$\mathrm{Bu}$ çalışmada; Kırıkkale Üniversitesi kampüs alanı araştırma noktası olarak ele alınmış, anma gücü $800 \mathrm{kw}$, kule yükseklikleri 60/73/75 metre olan Enercon-53 tipi rüzgar türbini kullanılmıştır. İlk olarak Hellman bağıntısı kullanılarak bölgenin sahip olduğu on metredeki ortalama rüzgar hızı, türbinin kullanılacağı kule yüksekliğindeki değerine dönüştürülmüştür. Hellman bağıntısı pürüzlülük katsayısı bölgenin özelliğine göre 0.15 olarak belirlenmiştir. Kule yüksekliklerine göre hesaplanan rüzgar hızı verileri Tablo III'de verilmiştir:
TABLO III

RÜZGAR HIZI DEĞIŞSIM DEĞELERI

\begin{tabular}{|c|c|}
\hline Yükseklik Değerleri $(\mathrm{m})$ & Ortalama Rüzgar Hozl (m/sn-yll) \\
\hline $\mathrm{h}=10$ & 4.5 \\
\hline $\mathrm{h}=60$ & 5.8876 \\
\hline $\mathrm{h}=73$ & 6.0633 \\
\hline $\mathrm{h}=75$ & 6.0880 \\
\hline
\end{tabular}

Rüzgar hızı dönüşümleri yapıldıktan sonra, Rayleigh olasılık yoğunluk fonksiyonu kullanılarak rüzgar hızlarının olasılıkları hesaplanmış, bu değerler toplam süreyle çarpılarak rüzgar hızlarının yıl içindeki esme süreleri bulunmuştur. Türbinden elde edilen enerji miktarı ise türbin güç eğrisinde, rüzgar hızına karşılık gelen güç değeri ile esme süresi çarpılarak hesaplanmıştır. $\mathrm{Bu}$ hesaplamalar türbinin üç ayrı kule yüksekliği için ayrı ayrı yapılarak enerji üretim miktarı bulunmuştur.

$800 \mathrm{KW}$ anma gücü ve $60 \mathrm{~m}$ kule yüksekliğine sahip Enercon-53 için yapılan hesaplamalardan yararlanarak türbin kule yüksekliğindeki rüzgar hızlarının yıl içinde görülme olasılıkları ve esme süreleri grafiksel olarak Şekil II'de gösterilmiştir.

ŞEKIL II

ENERCON-53, 60 METRE KULE YÜKSEKLIİĞİ ICIİN RÜZGAR HIZLARININ YIL İÇINDEKİ GÖRÜLME OLASILIKLARI VE ESME SÜRELERİ

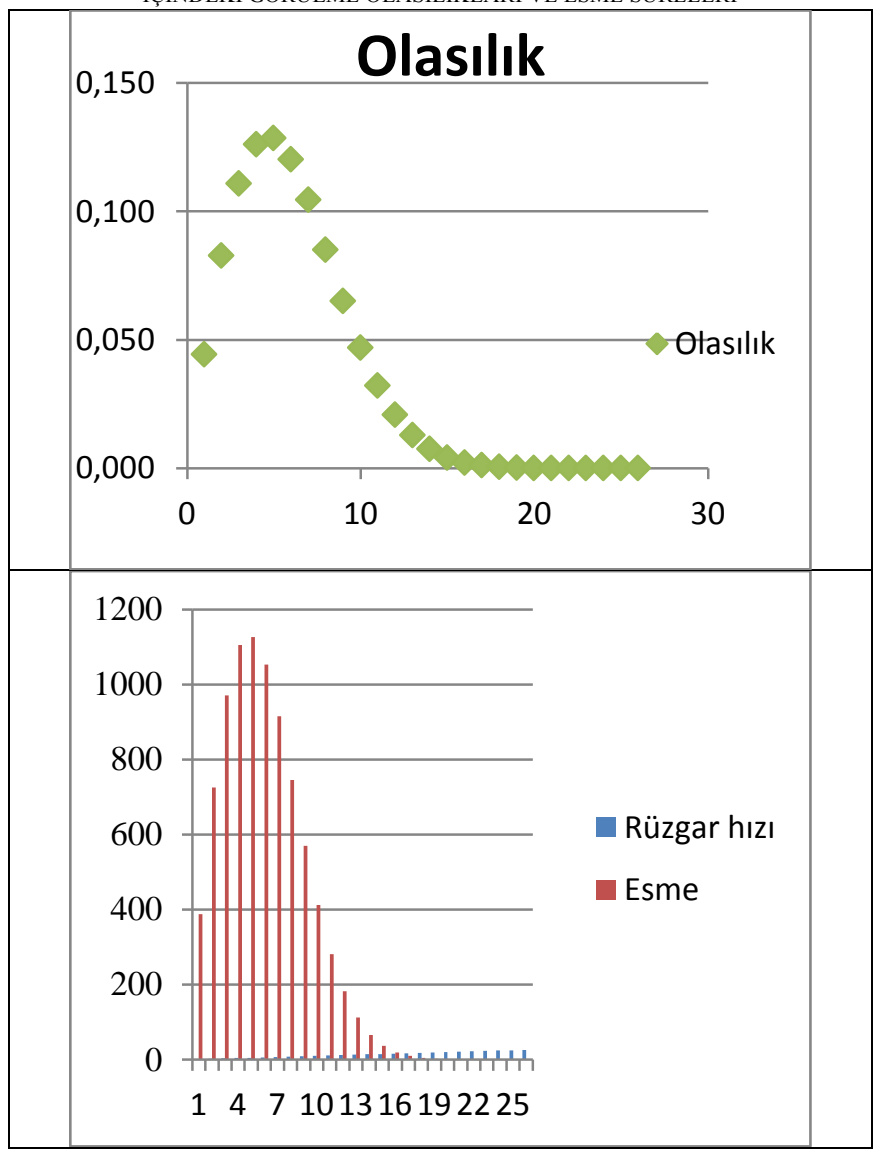


Bölgeden elde edilecek enerji analizi, Enercon-53 türbinimizin 73 metre kule yüksekliği için yapılmıştır. Bu kule yüksekliğinde rüzgar hızlarının y1l içindeki görülme olasılıkları ve esme süreleri Şekil III'de grafiksel olarak gösterilmiştir.

ŞEKIL III

ENERCON-53, 73 METRE KULE YÜKSEKLIĞI IÇCiN RÜZGAR HIZLARININ YIL ICINDEKİ GÖRÜLME OLASILIKLARI VE ESME SÜRELERI

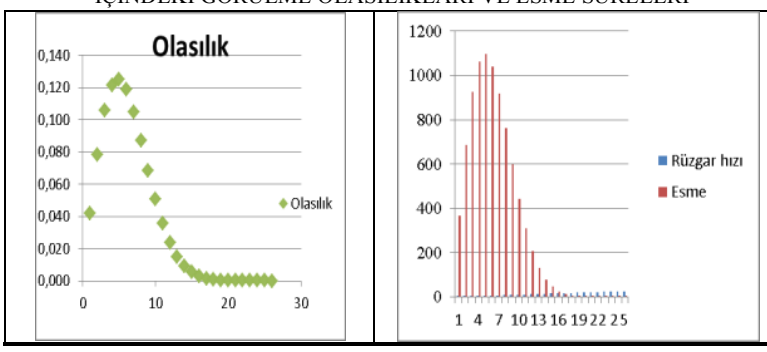

Son olarak, enerji analizi Enercon-53 türbinimizin 75 metre kule yüksekliği için yapılmıştır. $\mathrm{Bu}$ kule yüksekliğinde rüzgar hızlarının yıl içindeki görülme olasılıkları ve esme süreleri Şekil IV'de grafiksel olarak gösterilmiştir.

ŞEKIL IV

ENERCON-53, 75 METRE KULE YÜKSEKLIİĠI ICC̣IN RÜZGAR HIZLARININ YIL ICÇINDEKİ GÖRÜLME OLASILIKLARI VE ESME SÜRELERI

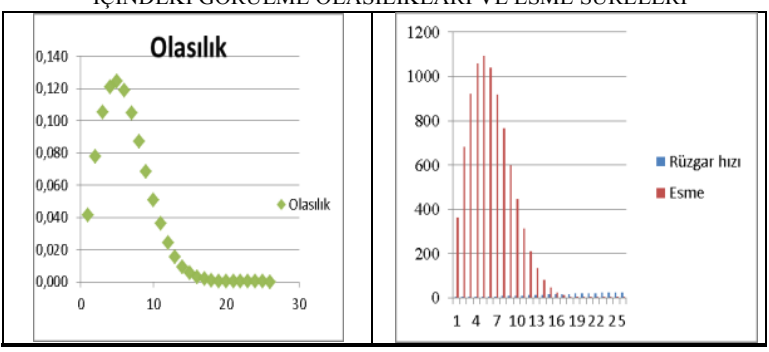

Tablo IV'de Enercon-53 türbini 60/73/75 metre kule yükseklikleri için kullanılarak bölgeden y1llık üretebilecek enerji miktarı ve kapasite faktör değeri verilmiştir. Literatürde Türkiye için 0,25 ve üzerinde bir kapasite faktörüne ait rüzgâr türbininin kurulumu ticari olarak uygun kabul edilmiştir [11-12].

TABLO IV

ENERCON-53 TÜRBİNi 60/73/75 METRE KULE YÜKSEKLIKLERI İÇIN ENERJI ÜRETIM MiKTARLARI VE

\begin{tabular}{|c|c|c|}
\multicolumn{3}{|c}{ KAPASITE FAKTÖRLERİ } \\
\hline $\begin{array}{c}\text { Kule } \\
\text { Yüksekliği } \\
(\mathrm{m})\end{array}$ & $\begin{array}{c}\text { Kapasite } \\
\text { Faktörü (\%) }\end{array}$ & $\begin{array}{c}\text { Enerji Üretim } \\
\text { Miktarl } \\
(\text { MWh })\end{array}$ \\
\hline$h=60$ & 0,263382 & 1845783,9 \\
\hline$h=73$ & 0,28048 & 1965600,9 \\
\hline$h=75$ & 0,28288 & 1982422,2 \\
\hline
\end{tabular}

Üretilen enerji miktarları ve yatırım tutarları kullanılarak yatırımların geri ödemesi bulunmuştur. Amaç, yaklaşık yatırım tutarlarında türbinin hangi kule yüksekliği kendini daha k1sa sürede amorti ediyorsa o yükseklik tercih edilmelidir.

Tablo V'de Enercon-53 türbini 60 metre kule yüksekliğine ait geri ödeme süresi yatırım miktarının \%30'unun öz kaynakla karşılanacağı düşünülerek ve türbinin yıllık gideri hesaba katılmayarak hesaplanmıştır.

TABLO V

60 METRE KULE YÜKSEKLİĞİ ENERCON-53 TÜRBIINİ, YATIRIMIN \%30'UNUN ÖZ KAYNAKLA KARŞILANMASI DURUMDA GERİ ÖDEME SÜRESI HESAPLANIŞI

\begin{tabular}{|c|c|c|c|c|}
\hline Yll & Maliyeti $(T L)$ & $\begin{array}{c}\text { Üretilen } \\
\text { Enerji } \\
(\text { KWh })\end{array}$ & $\begin{array}{c}\text { Üretilen } \\
\text { Enerjinin } \\
\text { Geliri }(T L)\end{array}$ & Kalan $(T L)$ \\
\hline 1 & $2.259 .180,00$ & 1845783,9 & $296.248,32$ & $1.962 .931,68$ \\
\hline 2 & $1.962 .931,68$ & 1845783,9 & $296.248,32$ & $1.666 .683,36$ \\
\hline 3 & $1.666 .683,36$ & 1845783,9 & $296.248,32$ & $1.370 .435,04$ \\
\hline 4 & $1.370 .435,04$ & 1845783,9 & $296.248,32$ & $1.074 .186,72$ \\
\hline 5 & $1.074 .186,72$ & 1845783,9 & $296.248,32$ & $777.938,40$ \\
\hline 6 & $777.938,40$ & 1845783,9 & $296.248,32$ & $481.690,08$ \\
\hline 7 & $481.690,08$ & 1845783,9 & $296.248,32$ & $185.441,76$ \\
\hline 8 & $185.441,76$ & 1845783,9 & $296.248,32$ & $-110.806,56$ \\
\hline
\end{tabular}

Aynı hesaplamalar türbinin diğer kule yükseklikleri için de yatırım miktarının \%30'unun öz kaynakla karşılanacağı düşünülerek ve türbinin yıllık gideri hesaba katılmayarak yapılmış, geri ödeme süreleri hesaplanmıştır.

Tablo VI'da Enercon-53 türbinin 3 ayrı kule yüksekliği için geri ödeme süreleri gösterilmektedir.

TABLO VI

ÖZELLIKLER GERI ÖDEME SÜRELERI

\begin{tabular}{|c|c|}
\hline Kule Yüksekliği & Geri Ödeme Süresi $(\mathrm{yll})$ \\
\hline $\mathrm{h}=60$ & $7.5-7.6$ \\
\hline $\mathrm{h}=73$ & $7.1-7.2$ \\
\hline $\mathrm{h}=75$ & $7.0-7.1$ \\
\hline
\end{tabular}

Tablo VI'dan görüldüğü üzere Enercon-53 türbini kullanıldığında en kısa sürede kendini amorti eden kule yüksekliği 75 metre, en geç kendini amorti eden kule yüksekliği ise 60 metredir. Sonuçlara göre, Kırıkkale Üniversitesi kampüsü içerisinde kurulması düşünülen tüm kule yüksekliklerindeki Rüzgar Türbin sistemleri geri dönüşüm süresi olarak uygun gözükmektedir.

\section{SONUÇ VE DEĞERLENDİRME}

Kırıkkale Üniversitesi'nin elektrik ihtiyacının rüzgar enerjisinden sağlanması üzerine yapılan bu çalışmada, Enercon-53 tipi rüzgar türbininin farklı kule yükseklikleri birbirleri ile karşılaştırılmıştır. Sonuç olarak, Kırıkkale Üniversitesi kampüsüne Enercon-53 tipi rüzgar türbininin 75 metre kule yüksekliği için kurulması durumunda diğer kule yüksekliklerine kıyasla daha kısa sürede amorti edeceği kanısına varılmıştır. Yapılan hesaplamalar sonucunda, incelenen 75 metre kule yüksekliğine sahip 
türbinin bölgeye kurulması durumunda kapasite faktörü 0,28288 olarak bulunmuştur. Türkiye için 0,25 ve üzerinde bir kapasite faktörüne sahip rüzgar türbininin kurulumu ticari olarak uygun kabul edildiğine göre bölgenin türbinin yatırım için uygun olduğu ortaya çıkmaktadır.

Santralin inşaatından önce yapılmış olan rüzgâr potansiyeli değerlendirmeleri ve yapılan doğru yaklaşımlar proje maliyetlerinin karşılanmasında ve yatırımcıya erken dönüşün sağlanmasında önemli etkendir. Mevcut rüzgâr karakteristiğine göre doğru türbin seçilmesi, türbinlerin sahaya yerleşimi, ulaşım, servis faaliyetlerinin doğru planlanması rüzgâr yatırımlarında önemli faktörlerdir. Bununla birlikte, sağlıklı bir yatırımın yapılabilmesi için uluslararası sertifikalı malzemelerle rüzgar türbinin konulacağ1 noktada 1 y1l süreli ölçümlerin yapılması gerekmektedir. Yapılan çalışmaların sürdürülerek ölçümlerin farklı bölgelerde daha yüksek ve daha uzun sürelerde alınarak tüm bölgenin detaylı araştırılması ve maliyet analizi yapılması neticesinde, daha doğru ve kesin değerlendirmeler yapılabilecektir.

\section{KAYNAKLAR}

[1] Bilgili M., Şahin B., Şimşek E., Türkiye'nin güney, güneybatı ve batı bölgelerindeki rüzgar enerjisi potansiyeli. Isı Bilimi ve Tekniği Dergisi, 30, 1, 01-12, 2010, ISSN 1300-3615.

[2] Anonim, Global statistics, Global Wind Energy Council (GWEC), http://www.gwec.net/global-figures/graphs/,(Erişim tarihi:01.04.2014)

[3] Türkiye Rüzgar İstatistik Raporu Ocak 2014, Türkiye Rüzgar Enerjisi Birliği (TÜREB), 36s., 2014.

[4] Enerji ve Tabii Kaynaklar Bakanlığı, Yenilenebilir Enerji Genel Müdürlüğü, http://www.eie.gov.tr.

[5] Gülersoy T., Çetin N. S., Menemen bölgesinde rüzgar türbinleri için Rayleigh ve Weibull dağılımlarının kullanılması. Politeknik Dergisi, Cilt 13, Say1 3, s. 209-213, 2010.

[6] Çubukçu M., Özdamar A., Enerji eldesinde rüzgar hızı ölçüm aralığı ve Hellman katsayısının önemi: Söke örneği.

[7] Özdamar A. ve Kavas G., Rüzgar türbini pervanesi dizaynı üzerine bir araştırma. Güneş Günü Sempozyumu Bildiriler Kitabı, s.151-160, Kayseri,1999.

[8] Masters M. G., Renewable and Efficient Electric Power Systems. 334-379, John Wiley Sons, Inc., USA, 2004.

[9] MÜSİAD, Müstakil Sanayici ve İşadamları Derneği Kırıkkale, http://musiadkirikkale.com/.

[10] Enercon Rüzgar Türbini Kataloğu, http://www.enercon.de/p/downloads/EN Productoverview 0710.pd f.

[11] Çetin N.S., Çelik H., Başaran K., Rüzgâr türbinlerinde kapasite faktörü ve türbin sınıfi ilişkisi. 6th International Advanced Technologies Symposium (IATS'11), 131-136, 16-18 May 2011, Elazı̆̆, Turkey.

[12] Erduman A., Kekezoğlu B., Durusu A., Tanrı̈̈ven M., Yenilenebilir enerji kaynaklarında $500 \mathrm{~kW}$ 'a kadar lisanssız enerji üretimi ve fizibilite analizi. 